\title{
Materiales didácticos para todos: el carácter inclusivo de fotovoz
}

\section{Teaching Materials for All: the Inclusive Character of Photovoice}

\author{
Angeles Parrilla LAtas $^{1}$ \\ parrilla@uvigo.es \\ Manuela Raposo-Rivas \\ mraposo@uvigo.es \\ Esther Martínez-Figueira \\ esthermf@uvigo.es \\ $M^{a}$ Isabel Doval Ruiz \\ mdoval@uvigo.es \\ Universidad de Vigo, Pontevedra, España
}

\section{Resumen:}

Fotovoz es una metodología de investigación-acción participativa que a través de un uso de fotografías y otros recursos producidos por los participantes promueve la reflexión y mejora sobre cuestiones relacionadas con sus propias necesidades y la comunidad a la que pertenecen. Este artículo, constituye un primer acercamiento a la reflexión sobre el papel que fotovoz puede jugar en la promoción de prácticas inclusivas. Basándonos en su desarrollo en una investigación llevada a cabo en seis escuelas de Educación Infantil y Primaria de una misma localidad gallega, se describe dicha metodología y se analiza su posible valor no solo como estrategia de investigación sino también como estrategia didáctica considerando su capacidad para crear y desarrollar procesos y materiales educativos pensados para todos y con la participación de todos. El análisis señala cómo en fotovoz se dan cita cuestiones conceptuales, de carácter epistemológico, ético y práctico, que convergen de manera clara con los principios

\begin{abstract}
:
Photovoice is a participatory action-research methodology that uses photographs and other resources produced by the participants to promote reflection and improvement regarding issues related to their own needs and their community. This article constitutes a first approach towards the reflection on the role that Photovoice might play in the promotion of inclusive practices. Based on its development in a study carried out in six schools of Primary and Secondary Education located in a Galician village, this methodology is described and its value is analyzed not only as a research strategy but also as a didactic strategy which leads to create and develop processes and educational materials designed for all and with the participation of all. The analysis reveals that in Photovoice there are conceptual, epistemological, ethical and practical issues that converge in a clear way with the principles and approaches of Inclusive Education. This allows us to rethink Photovoice as a participatory methodology with a remarkable
\end{abstract}

1 Dirección para correspondencia (correspondence address):

Ángeles Parrilla Latas. Facultad de Ciencias de la Educación y del Deporte. Universidad de Vigo. Campus A Xunqueira, s/n. 36005 Pontevedra (España). 
y planteamientos de la Educación Inclusiva. Esto nos permite resignificar fotovoz como una metodología participativa, de investigación y enseñanza-aprendizaje, de marcado carácter inclusivo.

\section{Palabras clave:}

Investigación participativa; educación inclusiva; fotovoz; participación; voz del alumnado; medios y recursos; comunidad. inclusive character suitable both for research and learning processes.

\section{Key words:}

Participatory research; inclusive education; Photovoice; participation; student voice; tools and resources; community.

\section{Résumé:}

Photovoix est une méthodologie de recherche-action participative. A travers un usage de photographies et d'autres ressources produites par les participants, elle favorise la réflexion et l'amélioration sur des questions relatives à leurs nécessités personnelles et collectives. Cet article constitue une première approche quant à la réflexion sur papier, et met en avant le fait que Photovoix puisse aider à la promotion de pratiques inclusives. Pour cela, nous nous sommes basés sur une recherche réalisée au sein de six écoles maternelles et primaires d'une commune galicienne. Nous décrirons la méthodologie choisie et analyserons sa valeur. Cette valeur apparaît non seulement comme une stratégie de recherche, mais aussi comme une stratégie didactique. Cette dernière considère la capacité à créer et développer des processus et des matériaux didactiques conçus par tous les élèves et pour tous. L'analyse indique que Photovoix travaille à la fois les questions conceptuelles, épistémologiques, éthiques et pratiques qui convergent avec les principes et les approches de l'éducation Inclusive. Ceci nous permet de penser que Photovoix est une méthodologie participative qui encourage le processus de recherche et d'apprentissage, avec un caractère inclusif remarquable.

\section{Mots clés:}

Recherche participative; éducation inclusive; Photovoix; participation; voix de l'étudiant; moyens et ressources; communauté.

Fecha de recepción: 16-5-2017

Fecha de aceptación: 27-7-2017

\section{Introducción}

Una de las cuestiones que de manera persistente se constata en la literatura sobre Educación Inclusiva, tiene que ver con la necesidad de incrementar los estudios y enfoques metodológicos que ejemplifiquen y analicen el desarrollo de procesos inclusivos en las aulas (Florian, 2015). La inclusión, como es sabido, no consiste sólo en abrir las aulas a alumnos/ as diversos, sino también y sobre todo en explorar y buscar alternativas a la enseñanza tradicional. Supone transformar las prácticas habituales en las aulas para dar cabida a nuevos métodos, procesos y formas de aprendizaje y relación, que se ajusten a la diversidad y las diferencias respetándolas y valorándolas. 
La aportación de este trabajo al conocimiento previo sobre el desarroIlo de la educación inclusiva en las aulas consiste en que aquí vamos a repensar fotovoz, un enfoque de investigación participativa -que hemos usado en una investigación previa-, como estrategia con capacidad de promover procesos metodológicos, de aprendizaje y recursos participativos e innovadores, pensados para todos y desarrollados con todos.

\section{Marco teórico}

\subsection{Fotovoz como metodología de investigación participativa}

Fotovoz se define en la literatura como una metodología de investigación participativa originalmente propuesta por Wang y Burris (1994), reconocida por la democratización del proceso de investigación que propone y por sus raíces epistemológicas en el modelo de conciencia crítica de Freire, la teoría feminista y la fotografía documental basada en la comunidad. Doval, Martínez y Raposo (2013) y Delgado (2015), destacan el carácter innovador e inclusivo de fotovoz como una metodología de investigación participativa y comunitaria que en su origen permitió dar poder y voz a aquellos que normalmente no son escuchados.

En fotovoz los participantes utilizan cámaras fotográficas para registrar ambientes o situaciones y generar datos, por lo que se implican directamente en el proceso de investigación. Las fotografías tomadas se convierten en elementos centrales que más tarde hay que textualizar y analizar mediante el desarrollo de procesos basados en el diálogo, la reflexión, la crítica y la intersubjetividad (Novak 2010). Esto permite amplificar la voz de los participantes ante los grupos que toman decisiones que son interpelados a actuar considerando las mismas. De este modo fotovoz promueve en su desarrollo cambios sociales y procesos de concientización, participación, liberación y emancipación.

Aunque se ha utilizado mayoritariamente con adultos, fotovoz aporta ventajas con respecto a otras formas de investigar con niños (Delgado, 2015; Lykes, Blanche y Hamber, 2003; McIntyre y Lykes, 2004). Entre ellas podemos destacar el papel protagonista que se otorga a los menores en el proceso de investigación, siendo reconocidos como coinvestigadores, participantes auténticos y no meramente simbólicos en el proceso bajo estudio. También se ha destacado el carácter no intru- 
sivo, accesible y familiar, para los niños/as del formato que utiliza (la fotografía), lo que facilita y acerca el proceso investigador al universo infantil. El acceso a su mundo a través de las narraciones escritas es sin duda otro valor añadido de fotovoz para investigadores de muy distintos ámbitos (pedagogos, psicolingüístas, sociolingüistas, antropólogos lingüistas, etc.). Fotovoz permite además una comprensión más ecológica del mundo de los participantes, que es estudiado a través de sus ojos, haciendo emerger insights, momentos y situaciones clave que podrían resultar invisibles a las personas ajenas a la situación analizada.

Sin embargo, como toda metodología innovadora que altera los constructos de la investigación tradicional ha recibido diferentes críticas. Sanon, Evans-Agnew \& Boutain (2014), Prins, (2010) y Wang \& RedwoodJones, (2001) coinciden al señalar los dilemas éticos que suscitan las cuestiones relativas a la privacidad y la confidencialidad de las fotografías, la existencia o no de consentimiento informado, o algún riesgo no previsto que pudiera derivarse del uso de las imágenes. Otros autores también plantean los retos metodológicos y técnicos (Evans-Agnew, Sanon, \& Boutain, 2013; Novek \& Morris-Oswald, 2012), sobre todo aquellos vinculados los cambios en la estructura de poder y en los roles tradicionalmente atribuidos a los distintos participantes, lo que puede generar resistencia y desconfianza entre la comunidad científica.

\subsection{Fotovoz como estrategia pedagógica-didáctica de enseñanza- aprendizaje}

Aunque fotovoz surge como método de investigación, ha ido demostrando su pertinencia como estrategia y recurso de enseñanza- aprendizaje (Zenkov \& Harmon, 2009; Cook \& Buck, 2010; Edwards, Perry, Janzen \& Menzies, 2012; Johnson, Pfister, \& Vindrola-Padros, 2012; Lichty, 2013). No obstante, hemos de reconocer que este uso ha sido minoritario, y está mucho menos documentado. Es por eso que nos centramos en el potencial y las posibilidades didácticas de fotovoz en este trabajo.

Vamos a destacar aquí algunas de las principales ideas fuerza o principios que ayudan a perfilar su potencial didáctico y educativo:

a) Una metodología basada en la participación activa y crítica del estudiante.

Fotovoz es una estrategia que promueve la construcción del conocimiento en base a la participación e interacción de los estudiantes. Asu- 
me el aprendizaje como acción socialmente construida en distintos contextos sociales, que a su vez mediatizan el mismo. Sirva de ejemplo el estudio de Spielman (2001) en el que los escolares utilizan fotovoz para el aprendizaje de la lecto-escritura. El proceso de aprendizaje se articula en torno a las fotos tomadas por los menores en los distintos escenarios en que se desarrollan su vida (familiar, escolar, social) y en la escritura y lectura de las imágenes tomadas por ellos mismos.

Es también una metodología que fortalece una posición crítica sobre las formas habituales de construcción de conocimiento (Giroux, 2013). Fotovoz considera a los estudiantes agentes de cambio y propone que es el alumno/a quien construye su propio conocimiento. Estudios como los de Schell et al. (2009) o Horwitz (2012) destacan esta idea y su potencialidad para desarrollar el pensamiento crítico y reflexivo. Cuando los niños/as "textualizan" las fotos, cuando elaboran narraciones y toman postura ante la cuestión de estudio, cuando reflexionan individualmente o en grupo, cuando debaten, discuten y dialogan entre iguales, están creando significados propios y situándose ante el conocimiento de manera crítica y activa.

b) Un proceso de aprendizaje apoyado en la creación y desarrollo de materiales visuales y narraciones, elaborados por el alumnado.

Garner (2014) ha dicho de fotovoz que puede considerarse una pedagogía innovadora, significativa y un proceso de aprendizaje contextual, al basarse en evidencias que son construidas y seleccionadas por los propios estudiantes para apoyar su proceso de aprendizaje. El importante proceso de producción de materiales que supone fotovoz, al descansar en las producciones visuales (fotografías) y narrativas escritas que los propios alumnos/as elaboran, suponen un uso de materiales alternativos y tecnologías asequibles y familiares, que vinculan el aprendizaje de los menores a sus propias elaboraciones. Fotovoz facilita además una estrategia visual para explorar, estimular y comunicar sus pensamientos (Nelson \& Christensen, 2009); para fomentar la creatividad y nuevos modos de aprender compartiendo el trabajo y los materiales creados con los compañeros/as.

c) Un planteamiento metodológico que crea un ambiente de aprendizaje construido en torno a relaciones en el aula basadas en la colaboración.

Como estrategia metodológica fotovoz además rompe con el esquema jerárquico de relación entre docente y estudiantes, y también entre 
los propios escolares, proponiendo un tipo de relación basada en el modelo de colaboración que se establece habitualmente en los equipos de investigación participativa (siendo los menores considerados co-investigadores). El aprendizaje interactivo y por descubrimiento que propone el uso de fotografías para aprender ha demostrado influir positivamente en la interacción entre iguales, así como reforzar el sentido de pertenencia al grupo y el conocimiento de los otros (Edwards et al., 2012).

d) Una estrategia que resitúa el papel del contexto y las experiencias subjetivas del alumnado en el proceso de aprendizaje.

Fotovoz permite utilizar en el aula información y materiales generados por los menores en los contextos social o escolar, lo que supone llevar estos y las vivencias de los escolares a las prácticas y experiencias de aprendizaje en el aula. El aprendizaje, se convierte así tal y como la teoría cognitivista propone (Vygotsky), en una actividad situada, inseparable de la situación en la que se produce. Por eso los procesos que fotovoz pone en marcha, permiten conectar con vivencias y experiencias habituales o rescatar y utilizar acontecimientos inesperados (sociales, emocionales, personales) que sirven para producir conocimiento y facilitar la transferencia de esos saberes. Todo ello ofrece además a los docentes la posibilidad de acercarse a la vida de sus estudiantes más allá de la escuela, al poder "verles" y "escucharles" como aprendices dentro y fuera de las paredes del aula.

e) Una herramienta de aprendizaje responsable que puede promover la transformación social y educativa.

Fotovoz también ha sido capaz de unir aprendizaje y transformación social y educativa, lo que le dota de reconocimiento como palanca de cambio y/o mejora. Puede ayudar a los menores a ir construyendo su identidad como ciudadanos activos, y a profundizar en la vida democrática. Nelson \& Christensen (2009) narran la experiencia desarrollada por estudiantes de educación secundaria que consideraban "en riesgo" por sus escasos logros académicos y su falta de participación en general con la escuela. Utilizaron fotovoz para representar las percepciones que tenían de sí mismos como aprendices y de su vida más allá de la escuela. La actividad dio pie a una serie de mejoras e innovaciones educativas gestadas por los propios alumnos/as. Por eso Cook \& Buck (2010) mantiene que esta estrategia permite a los escolares "participar de manera significativa en la comprensión, el cuidado y la transformación del mundo al que pertenecen" (p.35). 


\subsection{Marco empírico: Fotovoz en la escuela: una estrategia de indaga- ción capaz de crear procesos y materiales educativos para todos}

Este trabajo forma parte de un proyecto de investigación más amplio, denominado "Escuelas que caminan hacia la inclusión educativa: trabajar con la comunidad local, la voz del alumnado y el apoyo educativo para promover el cambio" (Parrilla, 2011), cuya meta fue desarrollar un proyecto de educación inclusiva local. En este proyecto participaron los seis centros educativos de educación infantil y primaria de la comarca de A Estrada (Pontevedra), entre los años 2009 y 2015. Junto a estos, también se involucraron diversas instituciones sociales y educativas de la misma comunidad.

Fotovoz fue un proceso desarrollado de manera conjunta por los distintos centros y agentes sociales dentro de esta investigación. Su finalidad fue conocer y dar a conocer la visión que los escolares de la localidad tenían sobre su participación en la escuela, planteando también como meta el diseño y desarrollo de procesos para mejorar la participación de los estudiantes en los centros educativos.

Ofrecemos a continuación una exposición resumida de cada uno de las fases desarrolladas, basadas en una adaptación de la propuesta original de Wang (1999), analizando así mismo el valor educativo intrínseco a cada una de ellas.

El trabajo se inició con una sesión de formación sobre los procesos de acción-reflexión en la investigación participativa (Nind, 2014) y las fases o momentos de la metodología fotovoz. En esta actividad participaron los docentes de los distintos centros mencionados, decidiéndose conjuntamente las cuestiones que guiarían el proceso. En concreto, se Ilegaron a acuerdos sobre:

- estrategia general: objetivos de fotovoz, participantes, temporalización, diseño del proceso de negociación en los centros y con las familias, presentación al claustro, y obtención de los consentimientos para fotografiar y ser fotografiados (verbales o escritos).

- cuestiones a investigar: la participación infantil en la escuela como tema de reflexión y análisis.

- procedimiento de recogida de información: cómo hacer las fotos de manera colaborativa, con qué recursos (cámaras desechables, teléfonos móviles, tablets, etc.).

- trabajo con la información recogida: cómo textualizar y co-textua- 
lizar las fotografías tomadas por los niños/as, cómo documentar, realizar informes, compartir y divulgar la información.

De este modo, fotovoz se concibió como un procedimiento para la recogida de información y mejora sobre la participación, en torno a seis fases representadas en la siguiente figura:

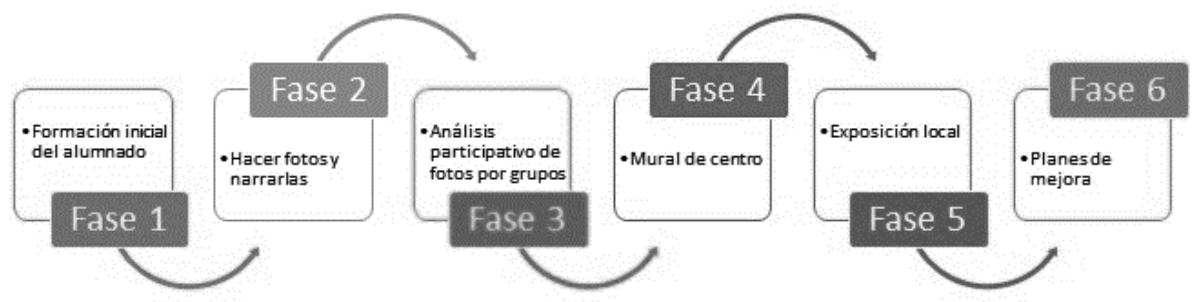

Figura 1. Fases del proceso de fotovoz. Elaboración de las autoras.

\section{Fase 1: Formación inicial del alumnado}

En cada centro educativo, siguiendo la propuesta de Kaplan y Howes (2004), se informa y forma al alumnado sobre fotovoz, la actividad a realizar y las cuestiones éticas y de privacidad (uso de la cámara, dónde pueden hacer fotos, respeto a los demás,...). Los docentes realizan ejercicios de lectura de imágenes con los niños/as para favorecer un enfoque crítico siendo las imágenes con las que trabajan aportadas por los menores.

Teniendo en cuenta los distintos tamaños y realidades de los centros participantes, se crean en cada uno seis grupos de estudiantes, que fueron identificados contando con la participación de los niños/as y buscando cierta heterogeneidad en su composición (no los mejores ni los más populares, no sólo los mayores...). El reconocimiento de los niños como co-investigadores llegó, en algún caso, a oficializarse mediante la firma de un memorandum o contrato investigador. 


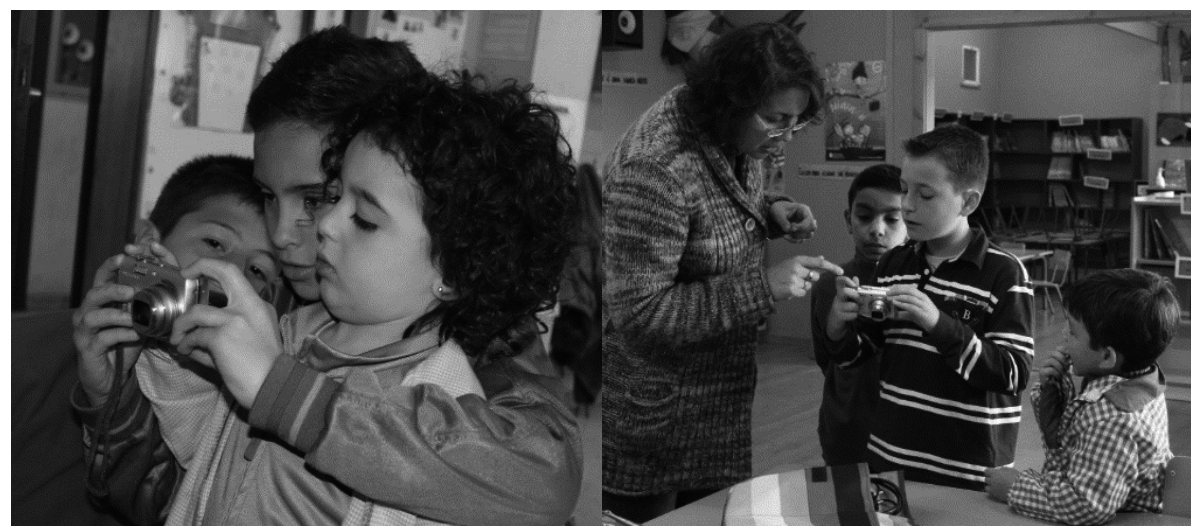

Imágenes 1-2. Formación del alumnado en manejo de cámaras fotográficas. Elaboración de las autoras.

El valor pedagógico de esta fase reside fundamentalmente en la formación y el desarrollo de la competencia digital del alumnado. Los niños/ as aprendieron que la imagen no es la realidad en sí misma, sino su representación y que como tal está cargada de valores y significados específicos. La narrativa visual aportada por la imagen, registra y transmite emociones, sentimientos, intereses, cultura, etc. De este modo, las actividades de lectura de imagen resultaron relevante tanto por su acercamiento a otros modos de comunicación y expresión personal como por su vinculación a la experiencia familiar o personal.

Asimismo, fotovoz ha permitido que trabajen juntos alumnos/as diferentes en cuanto a edad, intereses, estilos de aprendizaje, nivel sociocultural, etc. pues el planteamiento que se hace está basado en el valor de la diferencia y el apoyo mutuo que los escolares pueden darse.

La reflexión sobre el poder de la imagen, junto con la formación en torno a los límites en el uso ético de la fotografía, fueron dos elementos clave en el aprendizaje desarrollado en esta etapa.

\section{Fase 2: Hacer fotos y narrarlas}

En esta fase los grupos toman fotografías libremente en los centros sobre cuatro cuestiones relacionadas con su participación escolar:

a) "Lugares o situaciones en los que puedo participar"

b) "Lugares o situaciones en los que me gusta participar"

c) "Lugares o situaciones en los que me gusta menos participar"

d) "Lugares o situaciones en los que no puedo participar y me gustaría" 
Para cada una de estas cuestiones, los niños/as deciden qué fotografiar y cuándo lo harán. En el momento en el que toman las fotos anotan en un cuaderno de campo la motivación que les lleva a seleccionar cada una de las escenas fotografiadas. Al ir en grupo se ayudan en ambas tareas (la toma de fotos y la narración escrita). Todos estos materiales producidos por los niños/as se almacenan en un repositorio compartido.

A continuación, cada niño/a escribe de manera individual un título y un pie de foto con una breve narrativa alrededor de las escenas que ha fotografiado apoyándose en las notas del cuaderno de campo: ¿por qué he hecho esta foto? ¿qué significado tiene para mí?...

El valor didáctico de las actividades iniciadas en esta fase tiene que ver con el desarrollo de un proceso de indagación y reflexión sobre las cuestiones planteadas y cómo reflejarlas a través de la fotografía: qué fotografiar, por qué esa imagen, cómo hacerlo. También tiene que ver con el proceso de documentación y registro que los niños/as siguen, a través del uso del cuaderno de campo en el que se ensayan procedimientos para lo que más adelante será un análisis y reflexión sistemático sobre la información.

Las cámaras y el proceso fotovoz han servido también para capturar momentos cotidianos, cercanos a la vida de los alumnos/as, y reflexionar sobre ellos. Estos momentos dejaron de ser invisibles para ser pedagógicamente relevantes.

Al mismo tiempo, cuando se textualiza una foto estamos ante una ocasión de reflexión individual y grupal, de expresión, estructuración y articulación de ideas, que promueve un modo alternativo de comunicación a través de la fusión de imágenes y palabras, de narración visual y escrita.

Además, las acciones llevadas a cabo por los grupos de estudiantes permitieron la creación de un clima o ambiente de aprendizaje basado en unas relaciones más horizontales y participativas entre los escolares de distintas edades y cursos que trabajaron juntos, y entre docentes y estudiantes que se implican en un mismo proyecto desde una relación de igualdad.

\section{Fase 3: Análisis participativo de fotos por grupos}

En esta fase cada niño/a selecciona de entre todas las fotos tomadas, una por cada cuestión investigada. Escoge las más representativas de su idea de la participación en el centro. A continuación, se desarrollan procesos 
dialógicos en pequeños grupos con apoyo de los docentes. Cada uno le cuenta a los demás por qué esas fotos son las más importantes para él/ ella, la historia de la foto y lo que significa.

Con las fotos aportadas se identifican los temas generales que se repiten. Van apareciendo los vínculos entre las experiencias personales y las comunes. A continuación, se busca la historia compartida que hay detrás de cada foto, re-escribiendo en común el discurso narrativo que acompaña a cada imagen. Finalmente, se seleccionan, de entre todas, las imágenes textualizadas que mejor representan el sentir común del grupo en torno a la participación en el centro.

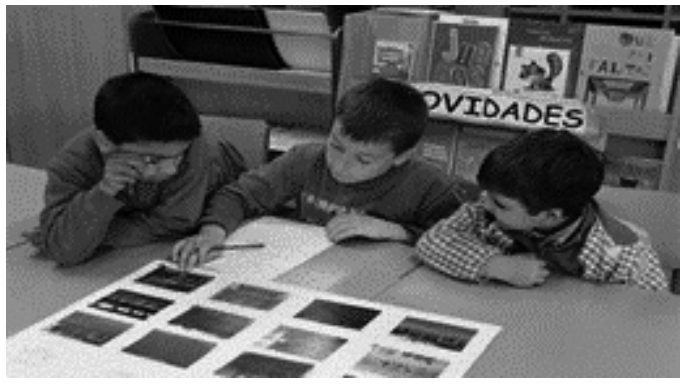

Imagen 3. Análisis participativo de fotos. Elaboración de las autoras.

El principal valor pedagógico de esta fase reside en que son los alumnos/ as los que analizan sus propias producciones alejándose de la tendencia habitual, en las que los adultos interpretan los registros y datos de los niños/as, limitando el proceso de participación de los estudiantes a la mera consulta. Aquí son los niños/as quienes desarrollan acciones de codificación de la información icónica y textual poniendo en marcha procesos de abstracción, descubrimiento de nuevos significados, contraste, transferencia y búsqueda de patrones comunes en los datos hasta crear una visión identitaria del grupo en torno a su participación en la vida escolar.

Además, el material generado sirvió para "dar voz", "hacer ver", lo silenciado, lo invisible, lo que pasa desapercibido a la mirada de un adulto pero es relevante para un menor. Sirva como ejemplo el rincón del reciclaje, que si bien es importante por el valor ecológico que enciera, fue identificado como imagen representativa de "lugares o situaciones en los que me gusta menos participar", por el olor así como por su aspecto descuidado y sucio.

Didácticamente esta fase supone también un compromiso importante 
con el desarrollo de procesos de aprendizaje en los que los alumnos/ as son los auténticos protagonistas y analistas de las cuestiones que les atañen directamente, y sobre las que pueden aportar el conocimiento experto derivado de su vida cotidiana. Asimismo, se sigue afianzando a través de la participación el sentido de pertenencia al grupo y la cohesión del mismo. Cuando un material, como en este caso, ha sido elaborado de forma participativa, crea una cultura colaborativa provocadora de un mejor conocimiento y conexión grupal.

Otro valor añadido de esta etapa se relaciona con los procesos inherentes al acto de la escritura colaborativa que permite que los alumnos/as se ayuden en los grupos heterogéneos en cuestiones lingüísticas. A través de las narraciones comunes se trabajan las dimensiones semántica, sintáctica y pragmática (desde la estructura del discurso y su significado a la ortografía, por ejemplo). De hecho, en uno de los centros participantes, una vez finalizado el estudio, se utilizaron las fotos textualizadas como material "auténtico" de lectura.

\section{Fase 4. Mural de centro: buscando una mirada compartida sobre la participación}

En esta fase, se trata de converger hacia una idea de la participación en el centro contando con todos los escolares en cada escuela.

Cada centro organiza un procedimiento de participación y consulta para identificar aquellas imágenes y textos que mejor representan las cuatro situaciones fotografiadas en las que pueden participar, en las que les gusta participar, en las que no les gustan y aquellas otras en las que les gustaría pero no pueden. El punto de partida es un montaje con una preselección de veinticuatro fotos textualizadas que darán lugar a un mural final de centro compuesto de doce escenarios sobre participación. Para seleccionar estas fotos se organizan actividades de difusión y participación como octavillas, charlas, debates, presentaciones multimedia, etc. Estas acciones concluyen con una Jornada de votación en el centro, siendo el mecanismo de voto utilizado decidido libremente: gomets, voto secreto en urna, carnet de votante, papeletas.... 


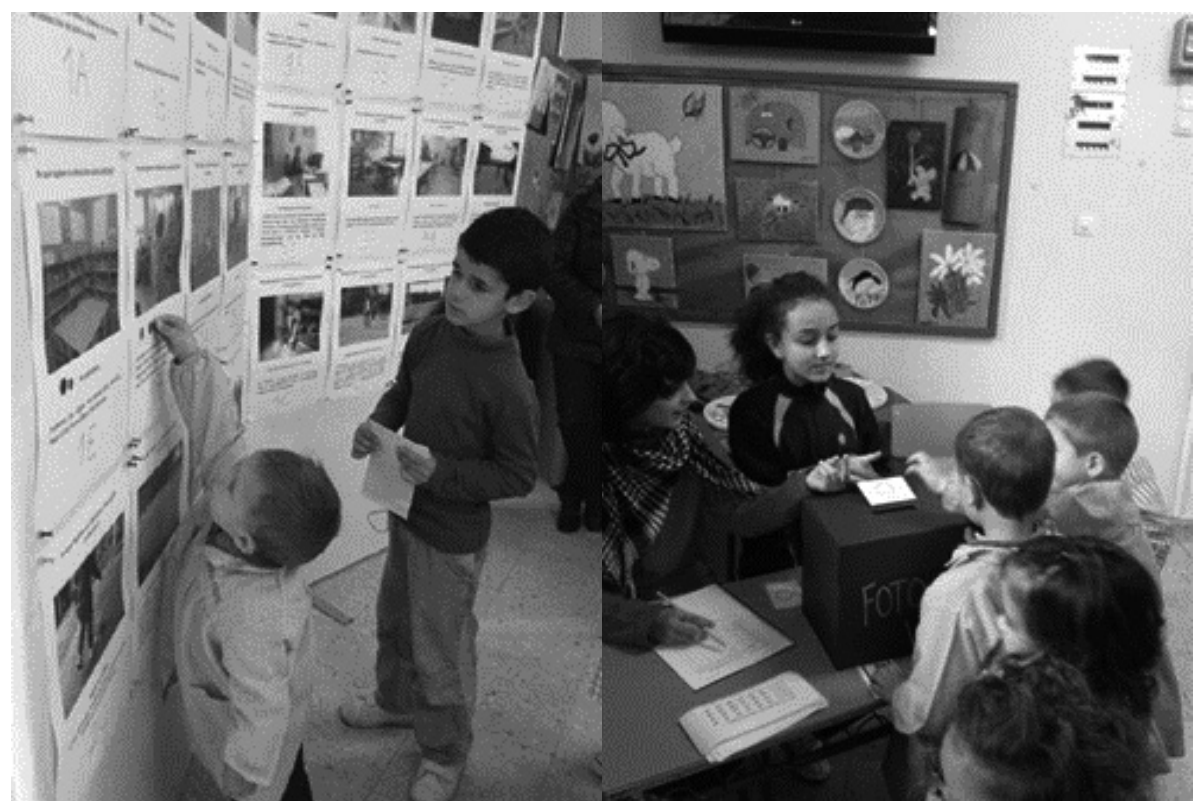

Imágenes 4-5: Proceso de votación en el centro. Elaboración de las autoras.

En este proceso precisamente reside el valor educativo de esta fase, es una aproximación a los valores democráticos y de ciudadanía deseables. A través del juego simbólico que representan la deliberación y la votación, se ensayan procedimientos y recursos que legitiman un proceso democrático en el que todos tienen la oportunidad de participar.

\section{Fase 5: Exposición local: construyendo un nuevo escenario de diálo- go sobre la participación}

Esta fase pretende por un lado, construir una mirada conjunta sobre la participación en todos los centros de la misma localidad, y por otro, compartirla y abrirla a la comunidad local.

Para ello, se hace en primer lugar, una puesta en común de los murales de todos los centros educativos siendo representada cada escuela por tres niños/as elegidos por ellos mismos. Estos menores analizan el conjunto de las fotos integradas en todos los murales, y seleccionan, categorizan y reescriben colaborativamente las imágenes junto con los textos que representan más acertadamente su sentir colectivo. El procedimiento de análisis y codificación de los datos fue similar al seguido en fases anteriores, si bien, la novedad en este caso reside en que este grupo está integrado por escolares de los diferentes centros participantes. 
En segundo lugar, se seleccionan seis fotos para cada una de las cuatro cuestiones sobre participación. Con ellas se organiza en la localidad una exposición interactiva denominada "La escuela vista por los niños/as", que recoge las veinticuatro fotos textualizadas. Además, se incluyen cada uno de los murales realizados en los centros participantes, un vídeo divulgativo que narra el proceso de fotovoz desarrollado, una proyección multimedia con todas las fotos que se tomaron y el libro de deseos sobre cómo les gustaría que fuese la participación en las escuelas de la localidad.
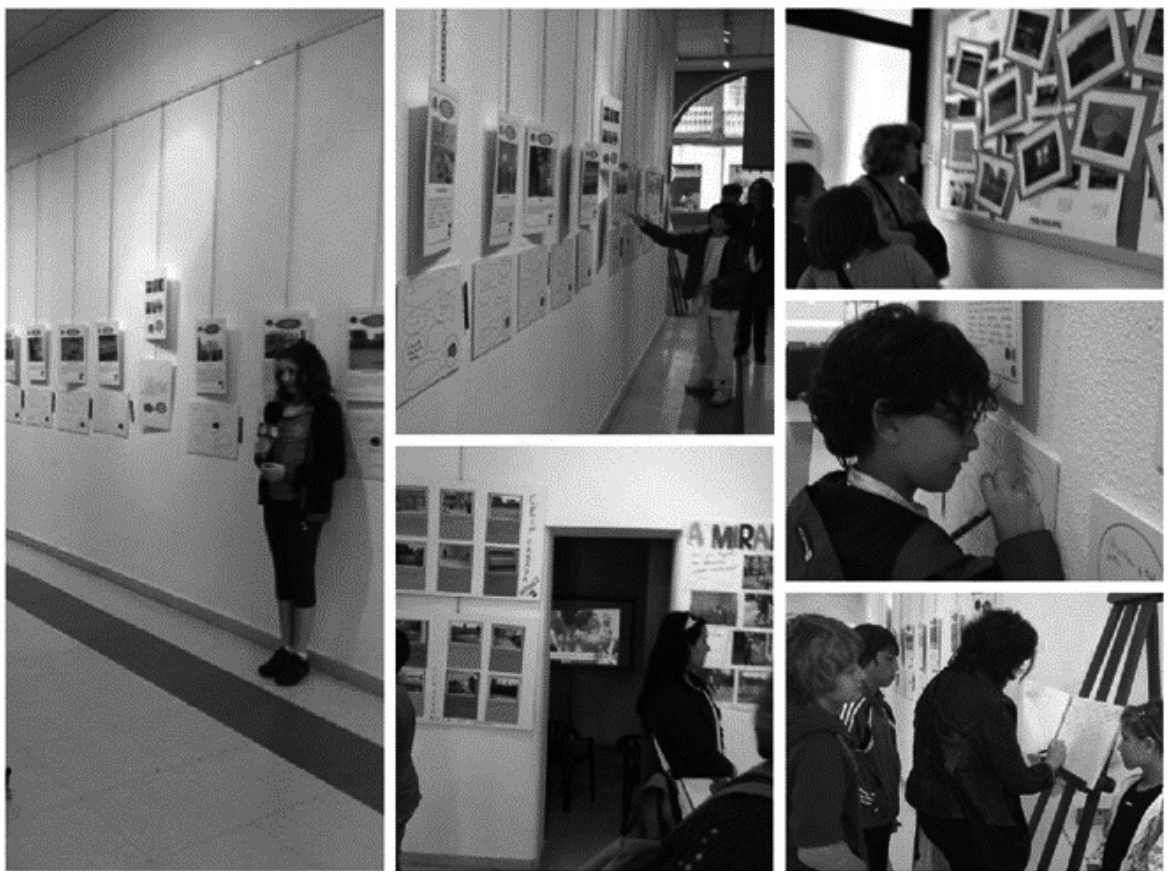

Imágenes 6-11. Diversos momentos de la exposición local. Elaboración de las autoras.

Educativamente, esta fase supone para los niños/as avanzar y profundizar en los procesos de análisis ya iniciados traspasando las fronteras del propio centro para trabajar en red, ampliando y contextualizando más su mirada sobre la participación.

Al mismo tiempo, la exposición local es un recurso educativo para toda la comunidad que contribuye a la creación de una cultura colaborativa entre estudiantes, centros, familias, ciudadanos y diferentes entidades locales. Dicha exposición abrió el proyecto al entorno, acercando es- 
cuela y comunidad. Esto es, la cultura de participación se transfirió a lo local, al invitar a todos los asistentes a interactuar a través de una serie de actividades que perseguían que el público fuese más que un mero espectador. Se daba así continuidad a la idea de "dar voz" y reconocer la participación de todos en un proyecto educativo inclusivo.

\section{Fase 6. Planes de mejora}

Una vez finalizada la exposición local, se analizan los datos derivados de la misma. En cada centro se procede a diseñar planes de mejora específicos en función de las fortalezas y áreas de mejora propias derivadas de su mural, que son complementadas con las demandas y necesidades derivadas del proceso local. La estrategia básica para el diseño de planes se apoya en grupos de discusión de los estudiantes con el profesorado si bien el procedimiento seguido varía de unos centros a otros.

Por ejemplo, entre otros planes de mejora, en un centro se reformularon los espacios y la planificación de las actividades durante el recreo para que fuesen más equitativos, y también se reorganizó la biblioteca escolar para que fuese accesible a todos los estudiantes.

Educativamente en esta fase los estudiantes toman conciencia de que el proceso de aprendizaje y participación puede contribuir a la modificación y transformación de la escuela y su entorno de aprendizaje. Lo que hacen los niños/as es importante, para ellos, para su centro, y para la comunidad. De hecho, se le entrega a los niños/as, al final de todo el proceso, un diploma acreditativo de su participación como co-investigadores.

\section{Conclusiones}

Este artículo se propuso repensar la metodología de investigación conocida como fotovoz tomando como pretexto su desarrollo en una investigación educativa. En el análisis realizado, hemos incidido en la exploración de su valor educativo y didáctico. Presentamos ahora para concluir algunas reflexiones finales que pretenden resignificar fotovoz como una metodología participativa de investigación y de enseñanza-aprendizaje de marcado carácter inclusivo.

Algunos de los argumentos que nos sirven para apoyar esta capacidad inclusiva que reconocemos en fotovoz se desprenden de las siguientes consideraciones: 
Fotovoz supone la construcción de un espacio no sólo para la participación, sino también para la coparticipación, como demanda la Educación Inclusiva. Esto significa un escenario de relaciones que supera la mera participación sumativa de individualidades, proponiendo una participación conjunta, compartida y multivocal. Se consiguen pues prácticas más inclusivas, que invitan a participar a todos los protagonistas (profesorado, familias, alumnado y agentes sociales), y reconocen su autoridad en los procesos de aprendizaje y cambio que les competen.

Otra de las claves comúnmente aceptadas en la promoción y favorecimiento de escuelas inclusivas, es la concreción de la participación en torno a culturas y redes de colaboración y aprendizaje dentro de los propios centros educativos, entre centros y con otras instituciones (Ainscow, 2016). Fotovoz tal y como se ha utilizado en nuestro estudio, ha permitido establecer una "cultura colaborativa" en los centros participantes y entre ellos, y ha promovido la actuación conjunta de estos como una comunidad de aprendizaje. Esto ha podido hacerse gracias a la participación compartida en distintos procesos que han trascendido los límites escolares invitando a la coparticipación inter-escolar, local y ciudadana. La formación común del profesorado en fotovoz, el análisis compartido de los datos, la elaboración de materiales transversales, o la exposición local, supusieron procesos de colaboración y aprendizaje conjunto de alto valor inclusivo en los centros y la propia localidad.

El reconocimiento del papel relevante de la participación de los niños/as en el proceso inclusivo es otra idea redundante en la literatura sobre inclusión, que considera que ésta tiene que ver con el incremento de prácticas educativas democráticas y deliberativas en las escuelas (Bragg, 2010). La inclusión exige no sólo recuperar la voz infantil, sino ofrecer un canal de expresión, y sobre todo de creación y producción compartida de conocimiento basado en el respeto a la diferencia, y el trabajo conjunto de alumnos/as diferentes. Fotovoz ha creado un contexto en el que ensayar y desarrollar prácticas educativas más democráticas. Esto, se refleja muy claramente en los procesos de elaboración de materiales desarrollados, de selección y codificación de la información, de votación, etc., que han reconocido el papel activo y protagonista de los escolares en los mismos.

Diversificación, personalización y adaptación, son sin duda otros elementos que definen toda práctica educativa que pretenda ser inclusiva. Fotovoz, en el caso que hemos analizado ha enriquecido y diversifi- 
cado la creación de materiales adaptados a las necesidades contextuales, singulares y colectivas de los participantes. Los materiales y recursos empleados, producidos y diseñados durante el proceso se han elaborado colaborativamente, vinculándose a situaciones del día a día escolar, lo que permite, incorporar a todos los escolares al proceso de enseñanzaaprendizaje. En concreto, los diversos materiales desarrollados pueden clasificarse según: a) su tipología, habiéndose creado materiales visuales, textuales y multimedia; b) su finalidad, respondiendo a distintos intereses, expositivos, formativos, evaluativos, de análisis de datos y de diseminación de resultados; y c) su usuario, pudiendo hablarse de materiales creados y usados con finalidad individual, colaborativa, inter-centros, comunitario o local.

El desarrollo de procesos de aprendizaje activo, en los que los escolares se implican y co-producen conocimiento según sus destrezas, estilos, capacidades, y experiencias, es otro de los lugares comunes al hablar de cómo desarrollar una educación inclusiva (Florian, 2015). La actividad investigadora que supone fotovoz incrementa las habilidades analíticoreflexivas, argumentativas y de indagación de los niños/as. También ha demostrado capacidad para dinamizar los procesos de aprendizaje y dotarlos de nuevos valores. Así por ejemplo, la fotografía, que suele ser un recurso de uso "receptivo" en las aulas (centrada sobre todo en imágenes de los textos) se convierte en fotovoz en un recurso creativo y activo, en un elemento crítico, vivo y dinámico de aprendizaje. Además, en nuestro estudio ha demostrado una potencialidad relevante para que algunos estudiantes que habían sido identificados por sus profesores/as como vulnerables, encontrasen la oportunidad para expresarse de un modo más sencillo, afín y empoderante. Pero además desde ese punto de vista didáctico la fotografía puede usarse con estudiantes, grupos, fines y en áreas instrumentales muy distintas (lengua, ciencias, matemáticas, etc.), para documentar, contrastar, investigar, identificar, reflexionar, etc.

La accesibilidad en los formatos de construcción del aprendizaje es otro principio básico para proyectar y diseñar aprendizajes desde la perspectiva inclusiva (Rose y Meyer, 2002). Fotovoz hace uso de un formato que puede calificarse sin sombra de duda de accesible (user friendly y low cost): cámaras, smartphones, imágenes y textos, son hoy en día recursos al alcance de todos. Esto facilita su normalización en contextos educativos formales y no formales, y la participación de todo el alumnado, independientemente de su edad, condición o nivel competencial, en 
los procesos que promueve. Fotovoz permite reimaginar los materiales y recursos inclusivos como recursos no dirigidos a grupos de población específicos, accesibles para todos, con un diseño co-participado por los niños/as, con significados auténticos y situados en su experiencia personal y comunitaria. Generando, en definitiva, materiales y recursos socialmente más justos.

Fotovoz tiene mucho de foto, pero también de voz. La convergencia de fotografías y narrativas escritas sobre las mismas, así como los debates y discusiones que acompañan su desarrollo, dotan a fotovoz de relevancia como estrategia de comunicación inclusiva. Cuando los escolares participan en la toma de fotografías, cuando crean y narran la historia propia que acompaña a sus fotos, o cuando negocian su significado, codifican, reescriben conjuntamente y seleccionan aquellas imágenes y textos con los que se sienten más identificados, están construyendo un proceso de aprendizaje que supone la puesta en marcha de muy distintas habilidades (instrumentales, sociales, actitudinales). Este proceso ofrece a los escolares la oportunidad de ser reconocidos y escuchados, usando los medios puestos a su disposición -digitales, escritos, oralespara construir y comunicarse desde unas narrativas propias, diferentes a las impuestas por los adultos en las relaciones de investigación y aprendizaje más convencionales.

Fotovoz permite así mismo una difusión inclusiva del conocimiento en la medida en que facilita su diseminación en formatos diferentes a los académicos tradicionales. En el caso que hemos analizado a fin de comunicar y compartir ese conocimiento con la comunidad local, se elaboraron informes con un estilo más visual y sonoro, considerando criterios de usabilidad para estimular el trabajo en grupo y la discusión (Nind y Vinha, 2012). En cuanto a la diseminación de los resultados, se han buscado modos imaginativos y creativos, más accesibles al mundo infantil como vídeos en el canal Youtube de algún centro, webs de los colegios, artículos en las revistas escolares, presentaciones orales y multimedia, exposición local, medios de comunicación locales, etc.

Por último, es destacable el papel nuclear que fotovoz, puede tener de vínculo y conexión entre escuela y comunidad. Como sabemos la inclusión educativa no es más que un medio para avanzar hacia el establecimiento de sociedades más reflexivas e inclusivas. Por eso las modificaciones que se realicen en las prácticas escolares si no se refrendan y continúan en el ámbito social, acaban "cortocircuitándose". En este 
sentido fotovoz a través de las distintas actividades que desarrolló tanto dentro como fuera de las escuelas, servió para dar a conocer y amplificar un modo de hacer participativo y colaborativo, para compartir los valores y la ética de la igualdad y la diversidad, pero también para apelar a la participación e implicación de otros agentes educativos en la necesidad de desarrollar un proyecto inclusivo de carácter local (Parrilla, MartínezFigueira y Zabalza-Cerdeiriña, 2012).

En definitiva, con este análisis esperamos haber iniciado un proceso de revisión y reconsideración del carácter de fotovoz, que nos gustaría pudiera ser refrendado o continuado en otros trabajos. El análisis desarrollado no obstante permite plantear, con las precauciones debidas, que en fotovoz se dan cita cuestiones conceptuales, de carácter epistemológico, ético y práctico, que convergen de manera clara con los principios y planteamientos de la Educación Inclusiva. Por ello pensamos que podrían ser considerados fundamentales para reconocer fotovoz no sólo como una metodología de investigación participativa y no sólo como una estrategia de enseñanza aprendizaje, sino también como una metodología inclusiva, que está llamada a jugar un importante papel en el desarrollo de prácticas educativas inclusivas.

\section{Referencias bibliográficas}

AINSCOW, M. (2016). Collaboration as a strategy for promoting equity i education: possibilities and barriers. Journal of Professional capital and community, 1(2), 159-175.

ALLEN, Q. (2012). Photographs and stories: ethics, benefits and dilemmas of using participant photography with black middle-class male youth. Qualitative Research, 12(4), 443-458.

BANKS, M. (2010). Los datos visuales en investigación cualitativa. Madrid: Morata.

BRAGG, S. (2010). Consulting young people: a literature review. London: Creativity, Culture and Education Series.

COOK, K., y BUCK, G. (2010). Photovoice: A community-based socioscientific pedagogical tool. Science Scope, 33(7), 35-39.

DELGADO, M. (2015). Urban youth and photovoice: Visual ethnography in action. New York: Oxford University Press.

DOUGLAS, H. (2002). Talking about pictures: a case for photo elicitation. Visual Studies, $7(1), 13-26$.

DOVAL, M. I., MARTINEZ-FIGUEIRA, M. E., y RAPOSO, M. (2013). La voz de sus ojos: la participación de los escolares mediante Fotovoz. Revista de Investigación en Educación, 11(3), 150-171.

EDWARDS, M., PERRY, B., JANZEN, K., y MENZIES, C. (2012). Using the artistic peda- 
Materiales didácticos para todos: el carácter inclusivo de fotovoz

angeles Parrilla latas, Manuela Raposo-Rivas, Esther Martínez-Figueira

Y M $M^{a}$ ISABEL DOVAL RUIZ

gogical technology of photovoice to promote interaction in the online post-secondary classroom: The students' perspective. Electronic Journal of e-Learning, 10(1), 32-43.

EVANS-AGNEW R., SANON M. A, y BOUTAIN, D. (2013). Critical research methodologies and social justice issues: A methodological example using photovoice. Philosophies and practices of emancipatory nursing: Social justice as praxis. London: Routledge.

FLORIAN, L. (2015). Conceptualising Inclusive Pedagogy: The Inclusive Pedagogical Approach in Action. Inclusive Pedagogy Across the Curriculum. London: Emerald Group Publishing Limited.

GARNER, S. L. (2014). Photovoice as a teaching and learning strategy for undergraduate nursing students. Nurse Education Today, 34, 1271-1274.

HORWITZ, J. R. (2012). Photovoice as a critical reflection methodology. En Agency through teacher education: reflection, community, and learning. Lanham, MD: Rowman \& Littlefield Publishers.

JOHNSON, G. A., PFISTER, A. E., y VINDROLA-PADROS, C. (2012). Drawings, photos, and performances: Using visual methods with children. Visual Anthropology Review, 28(2), 164-178.

KAPLAN, I., y HOWES, A. (2004). Seeing Through Different Eyes: exploring the value of participative research using images in schools. Cambridge Journal of Education, 34(2), 143-155.

LICHTY, L. F. (2013). Photovoice as a pedagogical tool in the community psychology classroom. Journal of Prevention and Intervention in the Community, 41 (2), 89-96.

LYKES, M. B., BLANCHE, M. T., y HAMBER, B. (2003). Narrating survival and change in Guatemala and South Africa: The politics of representation and a liberatory community psychology. American journal of community psychology, 31(1-2), 79-90.

LUTTRELL, W. (2010). A camera is a big responsibility: a lens for analysing children's visual voices. Visual Studies, 25(3), 224-237.

MCINTYRE, A., y LYKES, B. (2004). Weaving words and pictures in/through feminist participatory action research.Traveling companions: Feminism, teaching and action research. Westport, CT: Praeger.

NELSON E., y CHRISTENSEN K. (2009). Photovoice in the middle: How our students experience learning at school and beyond. New Zealand Journal of Teachers' Work, 6(1), 35-46.

NIND, M. (2014). What is Inclusive Research? London: Bloomsbury Academic.

NIND, M., y VINHA, H. (2012). Doing Research Inclusively, Doing Research Well? Report of the Study: Quality and Capacity in Inclusive Research with People with Learning Disabilities. Southampton: University of Southampton.

NOVAK, D. R. (2010). Democratizing qualitative research: Photovoice and the study of human communication. Communication Methods and Measures, 4 (4), 291-310.

NOVEK, S., y MORRIS-OSWALD, T. (2012). Using photovoice with older adults: some methodological strengths and issues. Ageing \& Society, 32(Part 3), 451-470.

PUTNEY, L. G. (2007). Discursive practices as cultural resources: Formulating identities for individual and collective in an inclusive classroom setting. International Journal of Educational Research, 46(3), 129-140. 
PARRILLA, A. (dir.) (2011). Escuelas que caminan hacia la Inclusión Educativa: trabajar con la comunidad local, la voz del alumnado y el apoyo educativo para promover el cambio. Memoria Técnica para proyectos tipo A y B. Referencia EDU201129928-C03-01.

PARRILLA, Á., MARTíNEZ-FIGUEIRA, M. E., y ZABALZA-CERDEIRIÑA, M. A. (2012). Diálogos infantiles en torno a la diversidad y la mejora escolar. Revista de educación, 359, 120-142.

PRINS E. (2010). Participatory photography: A tool for empowerment or surveillance? Action Research, 8 (4), 426-443.

ROSE, D., y MEYER, A. (2002). Teaching every student in the digital age: Universal Design for Learning. Alexandria, VA: ASCD.

ROYCE, S. W, PARRA-MEDINA, D., y MESSIAS, D. H. (2006). Using photovoice to examine and initiate youth empowerment in community-based programs: a picture of process and lessons learned. Californian Journal of Health Promotion, 4(3), 80-91.

SANON, M. A., EVANS-AGNEW, R. A., y BOUTAIN, D. M. (2014). An Exploration of Social Justice Intent in Photovoice Research Studies: From 2008 to 2013. Nurs Inq., 21(3), 212-226.

SPIELMAN, J. (2001). The family photograpy project: "We will just read what the pictures tell us". The Reading Teacher, 54(8), 762-770

WANG, C. C. (1999). Photovoice: A participatory action research strategy applied to women's health. Journal of Women's Health, 8(2), 185-192.

WANG, C. C., y BURRIS, M. A. (1994). Empowerment through photo novella: Portraits of participation. Health Education Quarterly, 21(2), 171-186.

WANG, C. C., y REDWOOD-JONES, Y. A. (2001). Photovoice ethics: Perspectives from Flint photovoice. Health Education \& Behavior, 28(5), 560-572.

WARREN, S. (2005). Photography and voice in critical qualitative management research. Accounting, Auditing \& Accountability Journal, 18(6) 861-882.

ZENKOV, K., y HARMON, J. (2009). Picturing a writing process: Photovoice and teaching writing to urban youth. Journal of Adolescent \& Adult Literacy, 52(7), 575-584.

\section{Notas}

El presente texto nace en el marco del subvencionado por el Plan Nacional de Investigación (EDU2011-2928-C03-01). En la actualidad, inspira algunas de las actividades desarrolladas en el proyecto Redes de Innovación para la Inclusión Educativa y Social subvencionado también por el Plan Nacional de Investigación (Ref. EDU2015-68617-C4-1-R). 
